\title{
SCOPE AND MEANING OF RURAL EXTENSION')
}

\author{
J. M. A. PENDERS \\ Inspector-General, Agricultural Advisory Services, Ministry of \\ Agriculture and Fisheries, The Hague
}

Since 1953 the International Agricultural Centre at Wageningen is organising an annual 3 till 4 week's international training course on rural extension in the month of July under the auspices of the Netherlands Ministry of Agriculture and Fisheries, the State Agricultural Ministry, the Food and Agriculture Organization of the United Nations and the Organization for European Economic Co-operation. This international summerschool on methods and programme planning in agricultural and home economics extension has been visited in the past seven years by about seven hundred participants from more than 50 countries. Approximately one third of the participants came from the so-called less developed countries. Considering the scope and character of the programme, dealing with principles which may be generally adopted, though adapted to the conditions prevailing in the different areas, it is the firm opinion of the organizers that this international course should not be limited to separate regions. As a matter of fact the training centre has stimulated by former participants the establishments of regional training centres on the same subject as for instance in Africa and in the same way also an international training centre on vocational teaching in agriculture in Switzerland. Since 1958 more topics on home economics were introduced in the programme leading to an integration of subjects in what may be called real rural extension. In 1959 about one third of the participants were home economists. The majority of lecturers are foreign experts including staff-members of F.A.O. and O.E.E.C. Ample time is provided for exchange of ideas and experiences among participants with the lecturers by making use of effective discussion techniques and a simultaneous translation equipment for the working languages English, French and Germain. The inclusion at free choice of a two till three day's field demonstration period under personal guidance of Dutch district agricultural advisory officers or home economists, field trips and local visits to research institutes in the "capital" of Dutch agricultural science enable the participants to study on the spot extension work and that of allied services as it is carried out under Dutch conditions. Since 1959 two day's workshops are held on farm management techniques resp. programme planning in extension. The rising number of participants - in 1959 the greatest number has been reached since the start - may lead to the conclusion that the programme has been kept flexible and fills obviously a need. This holds promise for the future and that Wageningen may add a little stone to the ever expanding building of international co-operation, marking the second half of our century. In the following some principles of rural extension, grown out of exchange of views amongst extension workers of many countries may be summarised.

1) Received for publication October 11, 1959. 
The organization, scope, objectives and working methods of rural extension services vary according to the economic and social conditions of the people concerned and the historical background which lefts its imprint upon the present extension services.

Therefore no uniform pattern should be adopted and possible changes are bound to be gradual. By expanding international cooperation an unanimity of opinion is however growing up amongst experts with regard to basic principles of rural extension, which can be adopted generally, though adapted to the conditions prevailing in the different areas.

\section{Objectives}

The objectives of rural extension are: to raise agricultural productivity and rural welfare, which objectives may be distinguished but are certainly interrelated.

Undoubtedly the primary concern of agricultural extension will always be to improve the technical and managerial side of farming in the field, barn and market place e.g. to raise agricultural productivity, including land, capital and labour productivity. Other important aims in terms of improved standards of living etc. are largely contingent on the increased efficiency of the farm as a sound and lasting base for the increasing earning power of the farm family. Since technical, economic and social factors in rural society are closely interrelated, the scope of rural extension ultimately has to cover all these aspects, and extension activities on those lines should be initiated, stimulated and associated as far as is possible.

There is much to commend a broad conception of extension and its approach to the farm family through the individual members of that unit, who are influencing each other. The improvement of the home should not lag behind the improvement of the farm, whereas also the future farmers and rural home makers should not be overlooked. Therefore apart from agricultural extension, adequate rural home economics and rural youth extension should play an important part vis-a-vis the rural population.

For socio-economic reasons special attention should be paid to less developed regions, backward farms and arrear sections of the rural population as otherwise the existing gap in development would widen. The integration of the agricultural industry in the national economy with its increasing international relationships and of the farming population in the total population of the country is the ultimate aim, which extension has to sustain. Finally, there is scope for extension in the field of consumer's education and public affairs by the appropriate agencies.

\section{WORKING PROCEDURE}

The working procedure of rural extension may be defined in simple but significant terms as "helping the rural population to help themselves". Rural extension must always be a "working together" programme: the professional extension worker and the rural population. Selection and training of volumtary local leaders is an important aspect of the work of professional extension personnel, also in view of the fact that with the increasing knowledge of the rural population the demand for advice will steadily grow. Intensive coopera- 
tion with the rural population is a conditio sine qua non for an effective extension service.

Regulatory, controlling and administrative tasks, which might hinder the growth of unconditional confidence and close working relationships between extension officers and the rural population or might occupy too large a proportion of the extension officers' workinghours, should be excluded from their duties.

\section{ReLation With TEACHING AND RESEARCH}

Resident vocational teaching, extension - as an out of school roadside education - and applied research are of equal importance. Close coordination and relationships between these services will improve their separate efficiency and the efficiency of these allied services as a whole. Resident teaching in agriculture and rural home economics is the main basis of an effective superstructure for rural extension. Experience has shown that the provision of more vocational teaching leads to a greater demand for extension. Close cooperation between extension and applied research will ensure a steady flow of research findings applicable in practice to the rural population and in turn guarantee that research workers are familiar with the most urgent problems facing the rural area which require solution. In this respect an efficient link would be provided by a staff of extension specialists in the most important subjects at the appropriate levels, forming an integral part of the extension service.

\section{Coordination}

Coordination in extension work is necessary to keep pace with the overgrowing specialisation in agricultural science and agriculture itself. It is obvious that a farm should always be viewed as a single business unit, rather thans as a number of uncoordinated sectors. There is much to commend the integral inclusion of farm management extension in agricultural extension work as the farm managerial capacity is a deciding factor in the achievement of greater productivity. Coordination will also allow for effective extension programme planning including the use of advisory aids and for training of extension officers. In the meantime however a highly decentralised system has to be followed in carrying out extension work to make it adaptable to the varying conditions of agriculture and rural population in the various regions and to cut out unnecessary bureaucracy.

As not only the farm but also the farm family is a unit particularly because the majority of farms are family-operated ones, cooperation, or at least close contacts, between agricultural, rural home economics as well as rural youth extension services are to be recommended.

\section{Financing}

Since rural extension is an important national service benefitting both the rural and the urban population, the responsibility for the major contribution towards the financing of rural extension work should be born by the national government. This will also ensure that extension is adequate for the needs of all groups of the rural population without any discrimination as to their socioeconomic status and that it will cover all rural districts including the least developed ones. In the event of price recession for agricultural products it would 
even be a wise policy to intensify rather than diminish rural extension and allied services.

When large and expensive rural development schemes are planned and carried out, educational facilities have to provide a relatively less expensive but indispensable supplementary means of working towards real progress. As a succesful extension depends to a great extent on the ability to recruit and retain suitable staff, adequate salary scales - to be in line with those offered for simular qualifications in other professions - and promotion prospects within the extension service, are important.

Serious attention has to be paid to proper office accomodation and adequate equipment and travelling facilities for the extension workers in order to ensure that they can perform their duties efficiently.

The number of fieldadvisers should allow for an adequate proportion of the farms tot be visited and for contacts with smaller farms and less progressively minded farm-families who are most in need for extension.

Although the financing of rural extension work is primarily a concern for the national government, determined efforts should be made tot stimulate public bodies, rural organisations and groups at the appropriate levels to make voluntary financial contribution in order to intensify extension and to allow for local interest and initiative.

\section{Public Relations}

In order to make both the general public and the farming population more fully aware of the importance of rural extension, public relations should be stimulated, securing the interest of influential groups and individuals by public education in which factual and objective evaluation is given of the aims, efforts, achievements and value or rural extension for both the rural and urban populations. To encourage both moral and financial support public relations should be emphasized as' rural extension - being educational of nature - is unspectacular, which applies likewise to agriculture and rural welfare.

\section{Training OF EXTENSION WORKERS}

There is no substitute for qualtiy of the extension worker. An extension worker is more than an expert in agriculture or rural home economics. His training should also prepare him to be a community organiser, an adult educator and a student of human behaviour in general. This is particularly true of the extension worker who comes most closely into contact with the farming population. Most of the extension workers come to the service as technicians rather than as educationalists. In extension staff training three categories can be destinguished with transitional stages between each other.

Pre-service training of extension personnel should generally be of a university standard, attaching full importance also to practical training and in post graduate courses to subjects like economics, sociology and extension education. It is necessary to emphasize this in view of the fact that :

a agriculture is becoming a highly complicated industry, combining both production and marketing;

b there are existing strong relationship between agricultural productivity and rural welfare with its various aspects which have to be "tackled"; 
c the ever rising educational level of the rural population gives raise to an ever growing demand for advice, both quantitatively and qualitatively.

When graduates from institutions for secondary vocational training are employed - which can be very useful in intensifying extension work - muck stress has to be laid on careful selection, induction training and supervision by academically trained personnel.

The training of new recruits in extension work deserves full attention as poor initial training can leave its mark on junior personnel for many years and may do harm to the prestige of the extension service. Induction training may be divided into fieldtraining - placing young recruits under the personal supervision of selected experienced senior officers interested in the matter - and formal training - by a continious course in which the trainees live together and rank as paid members of the extension service - in those subjects which were not or could not be emphasized adequately during the pre-service training.

In service training of extension workers, including the senior ones, is necessary too, since their efficiency depends on keeping abreast of modern technical developments and instructional methods. Well organised programmes by frequent conferences, refresher courses and study tours, both inside the country and abroad, the provision of extension reviews and close relationships between extension and research will prevent extension workers from becoming "blind" in regard to ever changing conditions, new research findings and developments in extension techniques.

\section{EXTENSION METHODS AND PROGRAMMES}

Extension work deals with people of different educational status, levels of living, cultural backgrounds, age and values. These differences demand a wide range of approach and a great variety of methods. As regards the number of people to be reached a distinction can be made between individual methods - particularly farm visits - groupmethods - meetings and demonstrations and mass methods.

With regard to the means a distinction can be made between natural object the written word, the spoken word and the picture, which can be used in a variety of forms and combinations to be carefully adapted to the subject and conditions prevailing in the repective regions. Experience has shown that a combination of methods is more effective than the use of a single one. There does not exist a uniform extension method or combination of methods to be adopted generally as a kind of prescription. Each situation requires careful consideration and previous investigation in order to be tackled effectively.

Finally, comprehensive programming is a basic working procedure of the utmost importance, if extension is to make its maximum contribution to rural progress. It should be based upon a careful analyses of factural situations to the technical, economic and social standards prevailing in the area. The programme should ultimately be of a comprehensive nature and include problems of interest to all members of the farm family and to all socio-economics groups, while at the same time it should be flexible enough to meet long-term needs, shortterm changes and special emergencies. It should be educational and should be the result of cooperation between the whole extension staff, the rural population and anyone who can contribute. It should take into consideration 
factors such as available personnel, finances, time and facilities, and it should therefore be divided into a long-term extension program and an annual working timetable, selecting for immediate action those problems which pay rather quickly at relatively little expense and are of more immediate concern and of most general interest, consequently being most likely to meet the changing needs of the people.

A systematic way in carrying out extension activities - which is not the same as a schematic 'way - will stimulate: the choice of the most effective combination of extension methods and in the mean time that the aims of the rural extension services are kept under constant review in order to ensure a reorientation of approach to ctrrent and urgent problems whereever necessary.

\section{Evaluation}

There is a need for critical thinking on what the extension services actually accomplish. Since the expenditure of public funds presupposes efficient administration and services to the general public, each country should make a periodic appraisal of its extension services, so as to show how successful it has been in relation to the money allocated to this form of education. By providing rational facts as to the merits of rural extension, public confidence and support can be gained. A periodic evaluation of extension work will also indicate how the efficiency of the extension service in adapting its aims and means to local needs and in concentrating its efforts may be improved. It may serve as a check on the relative effectiveness of the various methods and their use by the respective extension workers. It may also provide evidence of the value of the extension programmes planned and carried out, bearing in mind the fact that local conditions in each area may be vastly different and may be constantly undergoing changes.

Finally, it will help in furnishing essential data on the rural situation and stimulate in defining clearly the objectives of rural extension work.

\section{INTERNATIONAL COOPERAT ION}

No country has a monopoly of knowledge about good extension practices. There are marked differences between the rural extension services of each country, as related to the economic, social, cultural and historical background of the country and its people. But the very fact that these differences do exist is surely the strongest argument in favour of international cooperation. The more advanced countries can provide information on the successes and... failures of their own development programmes and on the type of situation in which one particular line of approach seems likely to be more effective than another. Conversely, they also gain from the less experienced countries by discovering new extension techniques more applicable to the backward or less productive areas of their own countries. While it may appear that rural extension is a monopoly of the western world, no one should be unmindful of the great contributions the East has made to progress in the past and still can make. The problems of less developed countries and of less developed rural regions in more advanced countries, where development has not always proceeded on harmonious lines, are in principle much alike.

There is a wide variety of effective procedures in sponsoring international 
cooperation on rural extension. These include the exchange of selected information on current activities through periodic international bulletins, the preparation of handbooks by joint study groups on valuable extension methods and procedures, periodic international meetings and refresher courses for extension leaders, specialists and practising workers.

The are common problems of a crucial nature as for instance coordination of rural extension, cooperation with allied services for résearch and teaching, extension evaluation, farmers participation, extension programme planning, training of personnel, which could be tackled effectively by a mutual exchange of ideas and experiences between extension leaders.

There are subjects requiring greater attention as for instance, farm management, agricultural economics and marketing which could be studied by extension specialists in countries which are eminent in that field.

Finally there is the wide and ever expanding field of extension methodology. International training courses and studies, forming an integral part of the continuing education of practising extension workers, could be initiated on a cooperative basis between countries.

Direct and personal contact will always be the basis for respectively effective cooperation. An exchange scheme allowing extension workers to both study and teach abroad, and the provision of facilities for training extension personnel in the extension services or universities of countries noted for their work in that field, would be a valuable means of fostering international cooperation in rural extension. Experience has taught us that much could be gained in the way of efficient international cooperation in rural extension if extension personnel with roughly similar qualifications and calibre were to attend meetings and courses, which would be organised for them and would have their subjects, and objectives clearly defined.

It is a real challenge to the extension services to support a lasting foundation for international cooperation in whatever section on the international scene their activities may lie by "helping the rural population to help themselves" in this respect too.

More then half of the world population still derive their livelihood from agriculture. Schemes for international cooperation also in integrating agriculture will have to be based ultimately on the respective populations, who will have to understand the meaning, necessity and consequenses in order to become willing and capable to sustain these schemes. Most of the organised rural extension services were initiated in the present century, marking the changeover to the scientific age in the field of agriculture and rural welfare. The second half of this century may widen their field of action in sponsoring international understanding, certainly more than mere knowledge, amongst the rural population. 